\title{
Patient Perspective: My Rare Disease Journey
}

Rachel Alvarez

Executive Director

Secretary, Board of Directors

Cure CMD

Congenital Muscle Disease International Registry

3217 E Carson St \#1014

Lakewood, CA 90712 USAcurecmd.org

rachel.alvarez@curecmd.org

My underlying diagnosis since birth was congenital muscular dystrophy not otherwise specified. Being born in 1970 meant that there was no genetic testing, no standards of care, and no true understanding of the pathology that separates one congenital-onset neuromuscular disorder from the next. Two muscle biopsies described histological abnormalities of small type 1 fibers, and were among the first of M.H. Brooke's cases described as congenital fiber-type disproportion (Brooks et al., 1973).

"Expect her not to survive beyond age 1," was what my young single mother was told in the first few months of my life when I wasn't strong enough to suck from a bottle. Just before my first birthday, the prognosis was, "expect her to never walk." After I achieved ambulation at 14 months, the prognosis was, "The oldest living patient we know with a condition like hers is age 27 . Most die of pneumonia."

I had spirometry around age 6 , and it was determined that things were fine, but that my mother should watch carefully for respiratory illnesses and make sure my vaccinations were always up-to-date. I was periodically sent to physical therapy, but once my mother learned the techniques to do at home, she became my physical therapist. She was also my nutritionist, psychologist, tutor, and drill sergeant. This child was not going to die on her watch. She made it her singular focus to exceed doctor's expectations at every turn. And it is because of her that I made it through childhood.

In my mid 20's, I began experiencing occasions during sleep where I would, "forget to breathe." These became more frequent in my 30's to the point that I was sleeping sitting up with a fan pointed at my face. I would frequently need to nap during the day, and experienced almost never-ending headaches. I lost a great deal of my mobility due to the ongoing fatigue that I was increasingly unable to adapt to. A sleep study revealed "sleep apnea" and recommendations in the future for oxygen and/or CPAP, in a report written by a sleep specialist who never laid eyes on me. If you know anything about neuromuscular conditions, oxygen and CPAP are exactly the wrong recommendations.

Fast forward to 2007. I had graduated from college, failed at one marriage and started another, and had been gainfully employed from the age of 17 . After aging out of the pediatric healthcare system, periodic visits to adult neurologists and pulmonologists to track progression and get advice for this congenital, unspecified neuromuscular condition that would cause death from pneumonia, were unfruitful and frustrating. Fortunately, progression was slow, and up until then, I maintained moderately independent function, ever-adapting my environment to serve my unique needs.

In December, 2007, I was delivered to the ED for the third time in as many months for what I now know was untreated respiratory failure. The first visit was the result of a 911 call when my husband came home to find me 
unconscious and unresponsive. The first two events resulted in a brief hospital stay to treat pneumonia, and provide respite with invasive ventilatory support. Both times, I was sent home with oxygen, the second time following a brief but failed trial on BiPAP. On this third visit to the ED, my cutaneous carbon dioxide was fluctuating between $60-87 \mathrm{mmhg}$ (normal range is $35-45 \mathrm{mmhg}$ ). I was fading in and out of consciousness, fully lucid one minute, and unconscious the next.

"Adult female with an unspecified congenital muscular dystrophy..." was overheard in the Emergency Department of a large hospital in Southern California, and piqued the curiosity of an emergency physician with a CMD-affected child of her own. While this was not her case, Dr. Anne Rutkowski asked her colleagues about the status and history of the patient, and approached a 37-year old woman and her husband to learn more. Dr. Rutkowski had spent the previous several years desperately searching for answers - and hope - about her daughter's condition. She had recently found two other families whose children also had a form of CMD, and they were discussing the idea of starting a nonprofit organization focused solely on this tiny piece of the muscular dystrophy umbrella.

Congenital muscular dystrophy (CMD) is a heterogenous group of ultra-rare neuromuscular conditions that typically present at birth, resulting from pathogenic mutations in one of more than thirty genes. Symptoms include muscle weakness, respiratory insufficiency, joint contractures, feeding difficulties, and in some cases, cardiac complications, and brain involvement.

In 15 minutes, this physician and mom, with no formal training in pediatric neuromuscular conditions, told me more about my probable condition than I had been told in the previous 37 years. Proximal weakness with distal laxity and joint contractures, check. Hyperkeratosis Pilaris, check. Normal intelligence, check. Respiratory insufficiency, check. She said she needed to look in on her cases and then verify some things, but that she would be back. Her attitude was oddly cheerful, leaving my husband and I a bit speechless.

In less than an hour, Dr. Rutkowski returned with several printed pages. "I think you have Ullrich congenital muscular dystrophy or Bethlem myopathy, but I'm guessing you're somewhere in the middle of those phenotypes. We of course will need to verify our suspicion with genetic testing, but l'd be surprised if we're wrong."

She proceeded to share that she had emailed a researcher with whom she had recently become acquainted in her quest to find answers for her daughter. He directed her to a recent publication characterizing the Collagen VI spectrum of disorders. My husband and I were shocked, overwhelmed, and not at all sure of what to make of this chance meeting, but for the first time in my life, there was something to act on.

Following, I was to be a resident of the ICU for almost eight weeks, where I was intubated, treated for pneumonia, given a PICC line because I couldn't maintain an IV for more than a couple of days, given 4 liters of whole blood, treated for a pneumothorax three weeks in, and trached.

Multiple trials on noninvasive ventilation (BiPAP) were unsuccessful. A combination of mask claustrophobia, the inability to exhale past an IPAP of even the lowest setting, and being so fatigued, doomed every trial. I was finally told that a tracheostomy was my only option, or I was choosing to die. That was truly the most vulnerable and terrifying moment of my life, not trusting the clinicians who were charged with my care, but having no one else to turn to. With literally no other choice, I reluctantly authorized the procedure. 
Despite being told I would likely never be able to speak while on a ventilator or eat anything substantial by mouth again, it was exhilarating to no longer be intubated. My husband was so happy to see me alert and animated in a way he hadn't for more than a year. I was transferred to a subacute facility for another six weeks to continue regaining stamina, learn how to function off breathing support during waking hours, and arrange for the delivery of a home ventilator.

The transition to home was rocky, but doable. Follow-up pulmonary function testing revealed that I was operating at $28 \%$ lung function (forced vital capacity), which had obviously been trending for several years. My pulmonologist said he was shocked at how I had still been able to function at this level for so long without breathing support.

A few weeks later, Dr. Rutkowski introduced my husband and I to her family. Sitting in a small breakfast cafe, she scribbled out a picture of the structure of muscle cells and how the various forms of CMD fit into the big picture - more professional versions of which I would eventually come to know almost by heart. But back then, with only two years as a Biology major before switching to Business Administration, it was largely a foreign language. Regardless, her enthusiasm and confidence that we could eventually solve all of this was infectious. Dr. Rutkowski shared plans for this new nonprofit she and two other parents were starting, to be called Cure CMD, focused on finding a cure for the five primary subtypes of congenital muscular dystrophy.

In the first four years following Cure CMD's official incorporation on May 19, 2008, it was an all-volunteer organization, run by parents, grandparents, and spouses of affected individuals - all of whom had jobs and loved ones with profound disabilities to care for. We funded our first research projects. We started a patient registry. We convened the first congress to develop consensus guidelines on the standards of care for CMD (Wang et al., 2010), and hosted the first scientific meeting dedicated solely to congenital muscular dystrophy. All the while, families living in siloes with unanswered questions, with care providers ill-equipped to manage these ultra-rare conditions - families who had never met another person with CMD - were coming out of the woodwork.

In early 2009, Dr. Rutkowski called to say she had identified a genetic testing opportunity for me - that a commercial lab was evaluating the efficacy of their new multi-gene sequencing "chip", and would cover the cost of testing if I authorized the use of my sample for validation. She came to my office to do the blood draw herself, and off it went via overnight mail. I tried not to wonder and worry as the months dragged on, to focus on my job and my volunteer work, and on staying healthy. Finally, in June 2010, the results were delivered. One copy of the c.842G>A (p.G281E) missense mutation was detected in the COL6A1 gene. At almost 40 years of age, I finally had a diagnosis - a name for the condition l'd lived with from birth.

Over the next few years, I became Cure CMD's first employee, hired to manage the exponentially growing patient registry. I learned the standard of care for someone with a neuromuscular condition: it didn't include CPAP, and it most definitely didn't include oxygen without positive pressure support. My carbon dioxide was so dangerously high because ventilatory support, not oxygen, is needed to combat hypoventilation due to weak breathing muscles. And as it turns out, untreated respiratory insufficiency is the primary cause of morbidity and mortality in neuromuscular disorders.

I ended up in the hospital several more times in ensuing years, experiencing several pneumothoraces over four months time, which prompted us to find others with COL6-CMD who were also experiencing these events. This led to a case report outlining the associated risk and management recommendations for pneumothorax in 
people with my condition (Fraser et al., 2017). In just a handful of years, I went from total ignorance and struggling to survive, to becoming an instrument for scientific inquiry and a lay expert in CMD.

As I became more involved and more educated about not only my own subtype, but the other subtypes of CMD as well, it became critically important to me to help educate affected individuals and their families about the need for proactive pulmonary surveillance and intervention. I came to know several pulmonologists with expertise in neuromuscular care, and peppered them with questions, requests for information, and reviews of our website guidance on the topic. At our 2017 CMD Scientific and Family Conference, I asked them to come up with a white paper on respiratory management for CMD - a white paper because there wasn't (and still isn't) enough evidenced-based data in CMD to publish a peer-reviewed paper. But anything, anything to help ensure my community wasn't going to continue to suffer from a lack of information like I did - putting this knowledge into the hands of families with the motivation to advocate for better care. And it's happened. We're already seeing a downward trend in hospitalizations for respiratory-related illnesses in people with CMD, and more people who have implemented care recommendations like daily use of cough assist.

A chance meeting in the Emergency Department with an extraordinary physician changed the course of my life. I know that I would not be alive today were it not for that encounter, and to think about all the ways it could have gone differently makes my head spin.

But so many people with an undiagnosed rare disease are not as fortunate as I was to have a fairy godmother course-correct their trajectory. Equal and timely access to diagnostics and healthcare continues to be woefully lacking in conditions like CMD, especially for those of color or lower socio-economic status. Of course, we can't expect every physician to recognize and know how to treat each of the more than 7,000 rare diseases, but ignorance about a rare disease can no longer be the reason that people are still dying from care that is anything less than informed and proactive.

Now as the Executive Director for Cure CMD, it is my privilege to serve my affected community. While we continue to fund research toward treatments, we also continue to advocate and educate, to make sure that no one finds themselves in the powerless position of ignorance that I found myself 14 years ago. But we're still losing kids and adults with CMD. Sometimes, regardless of the best possible care, we're just going to lose them, and I worry for my community every day. Improvements in care will never replace the need for treatments and cures, a feat exponentially more difficult to accomplish in rare and ultra-rare conditions.

The area of greatest need for CMD, as with almost every rare condition, is funding. Over the last fourteen years, Cure CMD has built a dedicated and passionate research network, and the infrastructure to support it through a patient registry, a biobank and tissue repository, a peer-reviewed grant funding mechanism, regular scientific conventions, and a central point of information for patients, families, clinicians, researchers, and industry. But the burden of funding research toward treatments continues to fall largely on affected individuals and their families, who are already struggling with the financial weight of caring for someone with a disability. It takes millions of dollars to advance research to the point of attracting and de-risking industry involvement in rare conditions, and while EMA/FDA incentives and amazing federal resources like the National Institutes of Health often make carrying the load a little less difficult, patient advocacy organizations continue to be the primary drivers of this desperate, painstaking, and very often, discouraging process. And even if we can attract industry to our tiny piece of the rare disease puzzle, there's only about a $10 \%$ chance we'll make it through clinical trials with an available treatment. But our affected community continues to persist, year after year, despite the challenges and setbacks. You will never find a more resilient and persistent group of people than those affected by rare disease. 
This desperate need for funding bleeds into other areas of our work besides advancing research toward treatments, like ensuring broad access to standards of care, advocacy and raising awareness, and ensuring that affected individuals and their families do not feel like they are the only one in the world trying to get through this incredible and terrible experience. And perhaps most of all, the need for funding translates into a lack of capacity for small organizations like Cure CMD. My tiny, overworked and underpaid staff continues to achieve extraordinary feats, riding on passion, determination and caffeine to keep the promise of our mission. We all wear many hats, pivoting at a moment's notice to switch gears as needed - often, outside of our comfort zone.

Despite advice to the contrary, I quickly learned to speak while on the ventilator, and eat whatever I want. Most people with CMD acclimate well to noninvasive ventilation - particularly those who are introduced to it well before it becomes life and death - and few choose a tracheostomy. But as I have come to use ventilatory support for more hours in the day, the benefits of a tracheostomy have outweighed the disadvantages. In 2007, I was given no choice, but today, the choice is mine to make, and I choose a trach.

I continue to defy my "expiration date", having turned 51 a few months ago, but it's always in the back of my mind: will today be my last day? Doctors should never have shared what my life expectancy was; it's a burden that people living with or caring for someone with a rare disease don't need, and there is no scientific measure for the ferocity of determination, and of hope.

This rare disease day, let's remember all who have come and gone in the fight for informed care, equitable access, treatments, and a cure. And let's redouble our efforts to ensure that those who are here now, and who are yet to come, will flourish because rare disease is no longer this thing no one knows or cares about. With 1 out of 10 people affected by a rare disease, it turns out that rare isn't all that rare after all.

Brooke $\mathrm{MH}$. Congenital fiber type disproportion. In: Kakulas BA, ed. Clinical studies in myology. Proceedings of the 2nd International Congress on Muscle Diseases, held in Perth, Australia, Nov. 22-29, 1971. Experta Medica 1973:147-59.

Wang $\mathrm{CH}$, et.al. Consensus statement on standard of care for congenital muscular dystrophies. J Child Neurol. 2010 Dec;25(12):1559-81. doi: 10.1177/0883073810381924. Epub 2010 Nov 15. PMID: 21078917. PMCID: PMC5207780.

Congenital Muscle Disease International Registry (CMDIR): cmdir.org

Fraser KL, et al. Pneumothoraces in collagen VI-related dystrophy: a case series and recommendations for management. ERJ Open Res. 2017 Jun 23;3(2):00049-2017. doi: 10.1183/23120541.00049-2017. eCollection 2017 Apr. PMID: 28660205. PMCID: PMC5482316.

2017 CMD Scientific and Family Conference (SciFam): scifam.info/2017

CMD Care Guidelines, Including the CMD Pulmonary Guide: curecmd.org/care-guidelines 


\section{COLD SPRING HARBOR Molecular Case Studies}

\section{Patient Perspective: My Rare Disease Journey}

Rachel Alvarez

Cold Spring Harb Mol Case Stud published online February 25, 2022

Access the most recent version at doi: $10.1101 / \mathrm{mcs} .0006205$

Published online February 25, 2022 in advance of the full issue.

Accepted Peer-reviewed and accepted for publication but not copyedited or typeset; accepted Manuscript manuscript is likely to differ from the final, published version. Published onlineFebruary 25,2022 in advance of the full issue.

Creative This article is distributed under the terms of the

Commons http://creativecommons.org/licenses/by-nc/4.0/, which permits reuse and

License redistribution, except for commercial purposes, provided that the original author and source are credited.

Email Alerting Receive free email alerts when new articles cite this article - sign up in the box at the Service top right corner of the article or click here. 